\title{
An Approach to Support Learning from International Experience with Water Policy
}

\author{
Leon M. Hermans
}

Received: 9 December 2009 / Accepted: 6 September 2010 /

Published online: 18 September 2010

(C) The Author(s) 2010. This article is published with open access at Springerlink.com

\begin{abstract}
International experiences with water policy and governance arrangements are shared through various international meetings and reports. The underlying assumption is that these experiences provide useful information to policy makers who are looking for ways to improve water resources management in their home country or region. However, little has been written about analytical support for these potentially interested policy makers. They have to reach informed decisions about whether or not to initiate a process of policy transfer, about which foreign experiences to consider and about what parts of those experiences to copy, adapt, or reject. Providing such analytical support is complicated by the involvement of multiple actors in water resources management, who do not necessarily agree on these decisions. This paper outlines an approach to offer analytical support to these multiple actors in the initial phase of a policy transfer process. The approach is applied to the case of the Büyük Menderes river basin in Turkey, where local policy makers were engaged in a policy transfer process related to the EU Water Framework Directive. It is concluded that the outlined approach can be used to inform local policy makers, as it yielded new and valid information in the case. In the absence of overriding political concerns, such information would lead to different decisions in various phases of policy transfer, when compared to a process that lacks this analytical support.
\end{abstract}

Keywords Policy transfer • Water policy • Dynamic Actor Network Analysis • Turkey $\cdot$ Lesson-drawing $\cdot$ EU Water Framework Directive

L. M. Hermans $(\bowtie)$

Delft University of Technology, Delft, The Netherlands

e-mail: L.M.Hermans@tudelft.nl 


\section{Introduction}

Experiences elsewhere offer a useful source of information for policy makers who are looking for ways to improve their local water policies or governance arrangements. Specific cases and experiences are showcased and discussed by various international organizations and at platforms such as the World Water Forums, at annual water weeks in Stockholm and at the World Bank, in the UN World Water Development Reports, the Millennium Ecosystem Assessment, the Global Water Partnership, and through OECD meetings and publications. In addition, many scientific studies are available that look in detail at one or more specific cases, trying to capture the mechanisms that have caused success or failure of water policies.

The wealth of international reports and websites shows that there is no shortage of interesting cases and good practices from various sources. Organizations and individuals are often quite willing to showcase and share their experiences in international forums. In fact, reporting experiences with water policy and management arrangements at international platforms can be considered a recognition of those experiences as hallmarks of an innovative spirit and of being at the forefront of water governance.

But what about the recipients of those experiences at potential target sites? How does a policy maker in a certain country, city or region, who is looking for ways to improve water governance, decide if experiences elsewhere with particular governance arrangements are worthwhile to adopt? How does one know if it is beneficial and possible to use experiences from abroad to improve local water resources management?

A part of the answer to these questions is found in a clear and sound analysis of the available experiences elsewhere. Such analysis helps to see if these experiences could work in other places as well and under what conditions, thus avoiding failures due to uninformed or incomplete policy transfer (Dolowitz and Marsh 2000). This part of the answer is covered not only by the many case descriptions and analyses, but also in methodological contributions on policy transfer and the "extrapolation" of policies from one place and time to another (Bardach 2004; but also Rose 2005 and Barzelay 2007).

However, if foreign experiences are to be transferred to a new country or region, they should ideally solve a problem there and they should be sufficiently congruent with recipients' prior beliefs and practices (Bennett 1991; Robertson 1991; Acharya 2004: 245). In fact, this is critical when it comes to making new water policy arrangements work in practice, as argued for instance by Swatuk (2005) and Van der Zaag (2007) for water reforms in Africa. Although such matchmaking is known to be important in policy transfer, there is little specific guidance as to how to deal with it. This papers aims to address this gap in analytical support for matchmaking in policy transfer. In doing so, it elaborates on the notion that such analytical support in water resources management needs to be context specific, and should seek to accommodate the different perspectives and perceptions that the various actors involved are likely to have (Hommes et al. 2009; Collins and Ison 2010).

In the remainder of the paper, a method is outlined and illustrated that should help potentially interested policy makers to reach an informed decision about the adoption of foreign policy arrangements. The paper is organized as follows: the second section contains a review of the literature on policy transfer to identify 
the insight and methodological support that is available, as well as the remaining gaps. In the third section an approach is outlined to address these gaps. The use of this approach is illustrated in the fourth section for the case of the EU Water Framework Directive as a possible policy framework for water resources management in Turkey. Based on this case application, the fifth section of the paper contains a discussion of the potential contribution of the approach to inform and support decisions on water policy transfer by local policy makers. The paper ends with conclusions on the benefits and limitations of the proposed approach.

\section{Policy Transfer and Lesson-Drawing}

\subsection{Concepts, Phases and Questions in Policy Transfer}

An understanding of how policy makers at a target site can make an informed decision about whether or not to adopt experiences from other sites, requires an understanding of the main elements involved in policy transfer. Relevant insights have been published for instance in work on policy transfer (Evans and Davies 1999; Dolowitz and Marsh 2000; De Jong and Edelenbos 2007), lesson-drawing (Rose 1993, 2005; James and Lodge 2003), policy extrapolation (Bardach 2004; Barzelay 2007), and policy or norm diffusion (Acharya 2004; Stokes Berry and Berry 2007).

Dolowitz and Marsh (2000) provide a conceptual framework for policy transfer that encompasses much of this literature. They use "a broad definition of policy transfer to refer to the process by which knowledge of policies, administrative arrangements, institutions and ideas in one political system (past or present) is used in the development of policies, administrative arrangements, institutions and ideas in another political system." (Dolowitz 2000, p.3). This definition is adopted here, meaning that policy transfer involves a source site that has potentially interesting experiences to offer, and a target site where there is an interest in learning from experience elsewhere (Bardach 2004; Barzelay 2007).

Dolowitz and Marsh (2000) identify a continuum from entirely voluntary lessondrawing to strictly coercive transfer through the direct imposition of policies or programmes. In this paper, the interest lies in policy transfer that involves at least a certain degree of voluntarism, even if it can include some elements of soft coercion such as pressures from abroad. In literature, these voluntary processes of policy transfer are also known as lesson-drawing (Rose 1993, 2005). In these voluntary processes of lesson-drawing and policy transfer, roughly four stages can be distinguished in coming to an informed decision regarding policy transfer.

The process starts with a first phase of initiation at a target site, where a decision is made to engage in a policy transfer or lesson-drawing process. Often, this starts with a recognition by politicians or a decision-making elite that there is a need for policy learning due the presence of a problem requiring attention (Rose 1993, 2005; Evans and Davies 1999; Bardach 2004). This is then followed by a second phase, in which one or more source sites and experiences are selected (Rose 1993, 2005; Evans and Davies 1999). In a third phase, the experiences elsewhere are analyzed and described in a way that allows for the construction of a "portable model that transcends its national context" (Rose 2005: 69). In these models, "mechanisms" are used as causal, explanatory devices (Bardach 2004: 209; Barzelay 2007: 527). Subsequently, in a 
fourth phase, these mechanisms are evaluated for use at the target site, resulting in a decision to adapt, adopt, or reject a policy mechanism, or to postpone a decision on this matter (Evans and Davies 1999; Bardach 2004).

Throughout these phases, policy transfer has both a political and an analytical dimension (Rose 1993, 2005). The political dimension refers to the involvement of multiple actors in policy transfer processes. It emerges as these multiple actors discuss, negotiate and influence the outcomes of decisions in various phases of the process (Bennett 1991; Robertson 1991; Evans and Davies 1999; Rose 2005). For water resources management, Swatuk argues that it is this political dimension that explains the many negative experiences with water reform in Southern Africa (Swatuk 2005).

The analytical dimension is concerned with the substance of policy transfer, referring to what is being transferred. In general, "models" and "mechanisms" are being transferred that describe and explain how policies, programmes, or governance arrangements work at a source site (Bardach 2004; Rose 2005; Barzelay 2007). These policy models and mechanisms are based on cause-and-effect chains, which build upon the notion of causal explanation as taken from policy evaluation literature (Bardach 2004, p.209; e.g. Chen and Rossi 1992; Argyris and Schön 1996; Pawson and Tilley 1997). In water resources management, examples of mechanisms that are frequently debated include market and pricing mechanisms, decentralization mechanisms such as irrigation management transfer and water user associations, and coordination mechanisms such as river basin organizations and national water authorities.

In sum, when it comes to support for policy makers at a target site, interested in learning from abroad, different phases can be identified in which both political and analytical questions need to be addressed. This is shown in Table 1. Many of the aspects in this table are well-covered in existing policy transfer literature, but some aspects have received less attention. These are highlighted and are addressed in the next section.

\subsection{Gaps in Analytical Support for Voluntary Policy Transfer}

The aspects that have received less attention in literature are mainly related to the analytical support for local actors in the initial phases of a policy transfer process. In most texts, these first phases are mainly described as a political process. Politicians or decision-making elites need to become dissatisfied, based on evidence that "something has gone wrong" (Rose 1993: 10). This is different from a critical analysis of the underlying reasons and causes for dissatisfaction. Similarly, the motives for initiating policy transfer that are provided by Bennett (1991) and Acharya (2004) are political, rather than analytical.

This limited attention for the analytical needs at the target site in the early phases of a policy transfer process also affects the subsequent phases in the process. Available guidance for analytical support in these subsequent phases takes the experience at the source sites as the main point of reference. The frameworks and methodological suggestions for analytic support in these phases discuss how to analyze policies at a source site in a more or less neutral and objective way, apparently taking the experiences as they present themselves to the analyst as an undisputed basis (Rose 2005; Bardach 2004; Barzelay 2007). However, given the 
Table 1 Phases and questions in policy transfer and lesson-drawing according to the literature (with gaps in literature indicated in grey)

\begin{tabular}{|c|c|c|}
\hline Phase & Political questions & Analytical questions \\
\hline $\begin{array}{l}\text { Initiation, } \\
\text { recognition }\end{array}$ & $\begin{array}{l}\text { Do we need lessons? Is there } \\
\text { sufficient sense of urgency among } \\
\text { decision-making elites to engage } \\
\text { in a lesson-drawing process? }\end{array}$ & $\begin{array}{l}\text { Do we need lessons? } \\
\text { Where do current } \\
\text { practices fall short of standards? } \\
\text { What standards? What are the } \\
\text { indicators that point to existence } \\
\text { or absence of problems? }\end{array}$ \\
\hline $\begin{array}{l}\text { Selecting } \\
\text { promising } \\
\text { source sites }\end{array}$ & $\begin{array}{l}\text { Evans and Davies 1999, Rose } 2005 \\
\text { What sources are accepted as } \\
\text { legitimate sources for } \\
\text { lesson-drawing? Ad-hoc } \\
\text { trial-and-error } \\
\text { (Evans and Davies 1999). } \\
\text { Political motivations } \\
\text { (Bennett 1991). Based on } \\
\text { geographical, psychological } \\
\text { or ideological proximity. } \\
\text { (Rose 2005) } \\
\text { Evans and Davies 1999, Rose } 2005\end{array}$ & $\begin{array}{l}\text { What source sites have } \\
\text { conditions that are } \\
\text { similar to ours? What } \\
\text { mechanisms are being used } \\
\text { elsewhere that could } \\
\text { also help solve our } \\
\text { problems? }\end{array}$ \\
\hline $\begin{array}{l}\text { Constructing } \\
\text { policy models }\end{array}$ & $\begin{array}{l}\text { What is the information delivered } \\
\text { by policy transfer agents? What is } \\
\text { the information filtered out by } \\
\text { 'gatekeepers' in the networks? }\end{array}$ & $\begin{array}{l}\text { What are the effects that we are } \\
\text { interested in? How do we weigh } \\
\text { these effects? What are the types of } \\
\text { costs that we take into account? } \\
\text { How do policies work at the source } \\
\text { site? What are the mechanisms and } \\
\text { context factors involved? What are } \\
\text { the effects and what does it take to } \\
\text { realize those effects? }\end{array}$ \\
\hline Evaluation & $\begin{array}{l}\text { Evans and Davies } 1999 \\
\text { Is this worthwhile? Should it be } \\
\text { adopted? (Rose 2005) What } \\
\text { parts do we want to transfer, } \\
\text { and to what degree? }\end{array}$ & $\begin{array}{l}\text { Bardach 2004, Rose 2005, Barzelay } 2007 \\
\text { "Could we make it work here?" } \\
\text { (Bardach 2004). What parts could } \\
\text { be transferred or adapted to our } \\
\text { local conditions? What are the } \\
\text { prerequisites of transfer? }\end{array}$ \\
\hline & Evans and Davies 1999, Rose 2005 & $\begin{array}{l}\text { Evans and Davies 1999, Bardach 2004, } \\
\text { Rose } 2005\end{array}$ \\
\hline
\end{tabular}

multiple dimensions, layers and players that are typically involved in water resources management, what parts and aspects of water policies are of interest, is as much a normative and value-laden question, as it is a matter of an objective assessment of cause-and-effect relationships. For instance, what effects does one take into account, what are the externalities that are to be considered, what are the appropriate scales in space and time in analyzing for instance the establishment of water user associations in a decentralization policy? 


\section{Analytical Support for Local Actors in the First Phases of Policy Transfer}

The previous sections showed that there is a gap in existing literature on policy transfer when it comes to analytical support for local policy makers at a target site in the first phases of policy transfer. In this section, an approach is proposed that should help to fill this gap.

\subsection{Needs and Requirements for Analytical Support}

Analytical support in the initial phases of policy transfer should help the multiple actors involved at a target site to identify, express, discuss and critically reflect on their needs for policy learning, in terms of pressing problems and promising solutions. This should help to get a better grip on the context-specific conditions at the target site, which is needed for informed decisions about promising source sites and the lenses through which to analyze available experiences elsewhere.

Although aimed at the analytical rather than the political dimensions in policy transfer, the political dimensions cannot be forgotten in thinking about a method for analytical support for the first phases of policy transfer. Agreement among local actors over the main aspects involved cannot be assumed, and political negotiations and consensus building may very well be necessary also in the early phases of policy transfer. Local actors may or may not agree on the main problems to be addressed, or on the interesting solutions that they would be willing to further investigate. Often, "the formulation of a [wicked] problem is the problem" (Rittel and Webber 1973: 161; cf. Hommes et al. 2009). This makes support for problem formulation in the early phases of policy transfer both more needed, and more challenging.

\subsection{Assumptions in Designing Analytical Support}

The existing analytical support in policy transfer mainly addresses the analysis of experiences at a source site, and uses causal models and mechanisms as its main instrument. Such causal models and mechanisms may be used to support not only an analysis of source site experiences, but also of target site needs. Whereas at the source site attention is focused on mechanisms as potential solutions, at the target site attention could be focused on mechanisms as causal explanations for existing problems, or as promising solutions. In fact, many of the known methods for problem formulation in policy analysis are based on the use of cause-and-effect structures, including causal maps and causally related means-ends hierarchies (e.g. Mingers and Rosenhead 2004).

Consensus on problem formulation can not be assumed to exist upfront (e.g. Hommes et al. 2009). Would it not exist, work on consensus building suggests that these processes are best started with a first phase of individual consultations, where each of the main parties involved can express its needs, concerns and opinions (Susskind and Thomas-Larmer 1999). In voluntary policy transfer, such consultations would clarify at the start why experiences from elsewhere are needed, by whom, and for what purposes. Comparing those needs and ideas would enable an assessment of the degree of consensus about the most pressing needs, potentially promising solutions, and relevant context factors. 


\subsection{Translating Needs and Assumptions into an Approach}

There are various methods that could be used to provide the required analytical support, including problem structuring methods (Mingers and Rosenhead 2004) and similar methods in water management such as activity modeling (Collins and Ison 2010), and actor analysis methods (Hermans and Thissen 2009). Of those methods, Dynamic Actor Network Analysis (DANA) (Bots et al. 2000; Bots 2009) offers specific support for both the reconstruction of conceptual causal models for different actors and comparative analysis of those models.

Dynamic Actor Network Analysis uses causal maps to represent the perception of an actor (see Fig. 2 for an illustration). These causal maps can be constructed in a specific DANA software environment, which links the different causal maps to an underlying database (Bots et al. 2000; Bots 2009). The method, through the use of the software environment, enforces a certain analytical rigor and consistency in the construction of the different causal maps, and enables an analyst to quickly perform a comparative analysis of the constructed maps, assessing among others agreement and disagreement among actors, the importance of objectives and the frequency with which policy instruments are mentioned.

The use of this method combined with the existing guidance for analytical support in the later stages leads to the following approach:

1. Conduct individual interviews with representatives of key actors in the field, using a short list of (semi) open questions that cover possible needs and directions for policy transfer, as well as underlying causal explanations

2. Construct causal maps to represent the perceptions of actors based on these interviews

3. Comparative analysis of causal maps, to arrive at an overarching diagnosis of the (consensus about the) need for policy transfer

4. Use this diagnosis as starting point in searching for possible source sites that show similarities on important conditions, or promising solutions for the identified problems.

5. Formulate policy models of the experiences elsewhere, using causal maps or other formats that help to describe the main mechanisms and context factors involved, in line with the prescriptions offered by Rose (2005), Bardach (2004) and Barzelay (2007).

6. Evaluate the available experiences and suggested mechanisms against criteria and conditions that are deemed important at the target site. These might be derived from the causal maps constructed during the initial stages, possibly complemented by additional elements that have emerged during the process.

Figure 1 maps the steps in this analytical approach to the main phases in policy transfer processes that are recognized in literature. This shows that the first three steps in this approach are new. With these new steps as a basis for the initial phase, also the subsequent phases of source site selection, model construction and evaluation will differ. Each of them should refer back to the analysis done in during the initial phase, in an iterative process.

Comparing the analytical approach to the known phases in policy transfer and lesson-drawing also clarifies that this analytical approach does not specifically address the political dimension in policy transfer processes. In most cases, a political 


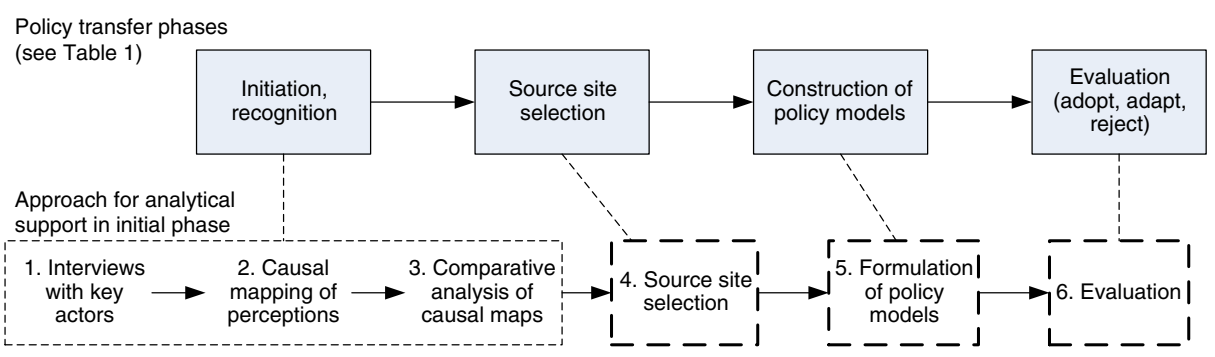

Fig. 1 Steps in the developed approach mapped to the main phases in policy transfer

and an analytical dimension will be present, with room for influences from both. In cases where the political dimension is so dominant as to override all analytical and substantive concerns, the developed approach is of little use. Unless of course as a political tool to sell a politically motivated decision to a broader audience. However, for the majority of processes that feature both analysis and politics, the approach is expected to provide a useful analytical basis to local actors.

\section{Case Application: the EU Water Framework Directive in Turkey}

In this section, the usefulness of the approach outlined above is explored for a case in Turkey. The selection of this case was based on the requirement that it should involve multiple actors who were interested to evaluate foreign experiences as a way to improve local water resources management. In addition, the selection of the described case in Turkey was driven by mundane criteria of access and opportunity.

In the continuum between voluntary and coercive policy transfer, this case can be positioned somewhere in the middle. There were important external pressures on the target site actors to seriously consider an available policy framework in the form of the EU Water Framework Directive. This means that in this case the fourth step in the approach, the selection of a source site, was already decided upon before the case work was started. This is not in line with prescribed approach that is explored here, but it is a helpful feature to evaluate the usefulness of the developed approach. It enables a comparison of the actual decision to select an EU Directive as a source site, without analytical support in the initial phase, against considerations raised by a more careful analysis of the needs at the target site. After a brief further introduction of the case, the remainder of this section follows the steps of the approach prescribed above.

\subsection{Background of the Reported Case}

The case study findings were obtained as part of a project that started in 2002 to support Turkey with the implementation of the European Union Water Framework Directive (EU 2000). The project focused on the Water Framework Directive as a framework for water policy that should be adopted by Turkey if it were to join the European Union, as part of the acquis communautaire (cf. Rose 2005, 87-88), and as a framework that could help to further improve the standard of water governance in Turkey. Within the project's two year time frame, it could not aspire to cover the 
complete Water Framework Directive, and the project focused on the elements that would be most important in the early phases of adoption.

In the project, the Büyük Menderes river basin was selected as a pilot river basin, to provide local experiences with river basin management according to the Water Framework Directive in Turkey (see location map in Fig. 2). This river basin covers an area of almost $25,000 \mathrm{~km} 2$ across six different provinces and contains approximately 2.5 million inhabitants. The main land uses are agriculture and forestry. Economic activity is mainly related to agriculture, textile and leather industries, and tourism. The delta of the river basin is a wetland of international importance. More details on this case can be found in Hermans and Muluk (2002) and Hermans (2005).

\subsection{Steps 1 and 2: Individual Interviews and the Construction of Causal Maps}

A total of nineteen interviews were held with actors who represented several interests and sectors in the river basin, such as the chambers of agriculture and of commerce and industries, the provincial governor, irrigation unions, and several provincial and/or regional directorates of government agencies, including those responsible for environment, state hydraulic works, forestry and tourism. Interviews were held in two provinces, which together covered most of the area in the river basin: the more downstream province of Aydin and the more upstream province of Denizli. Twelve interviews were held in Aydin, which was not only the seat of provincial organizations but also of some regional directorates that spanned different provinces. Seven interviews were held in Denizli.

Interviews were held by two analysts and actor representatives were asked to give their views on the most important problems related to river basin management

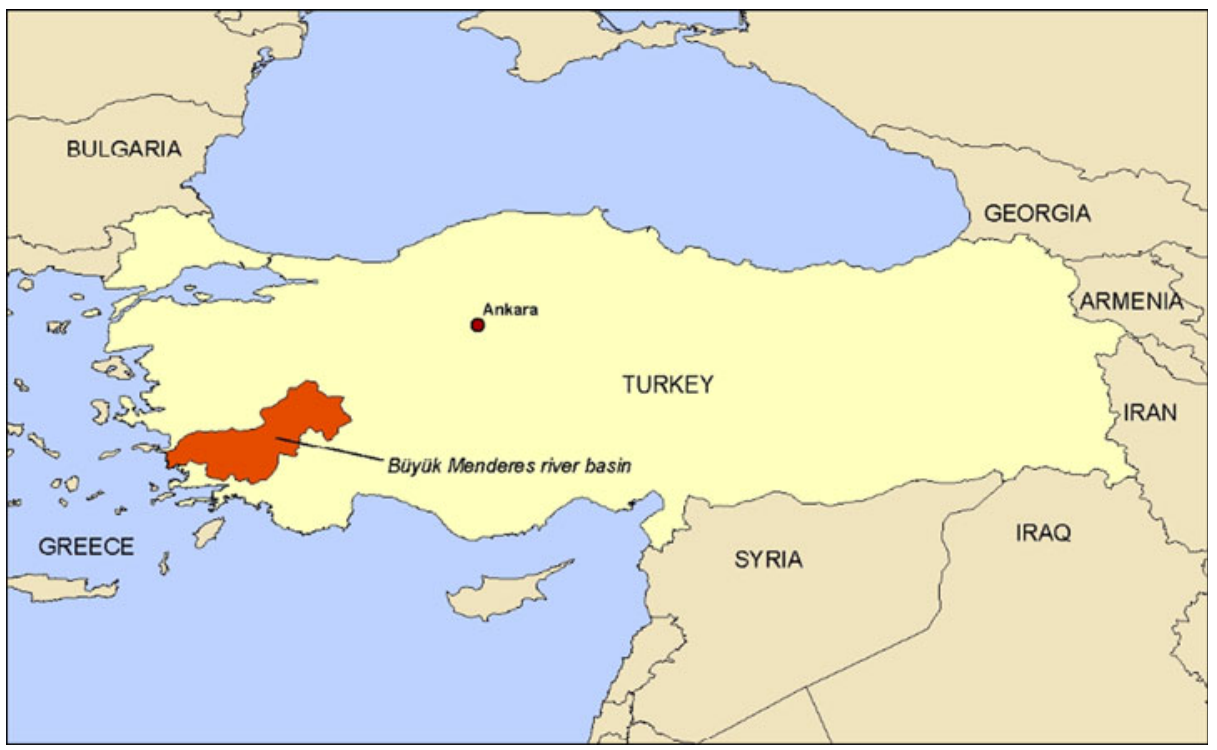

Fig. 2 Location of Büyük Menderes river basin in Turkey (Hermans 2005) 
in Turkey, their causes, and solutions. Also, the use of a river basin management organization as a possible mechanism for coordinated and integrated river basin management was discussed, if the issue had not been raised by respondents spontaneously. The results of these interviews were captured in transcripts. These transcripts were then translated in causal maps in the DANA software environment (see Fig. 3 for an example). These causal maps contained the ideas of a respondent about the main objectives that were at stake, the factors that affected these objectives, and the instruments of various actors to influence the realization of objectives. The translations of transcripts into these causal maps by the first analyst were checked by the second analyst. Both transcripts and causal maps were sent back to the respondents for verification.

\subsection{Step 3: Comparative Analysis of Causal Maps}

The resulting nineteen causal maps provided the basis for a comparative analysis, to assess the needs and the conditions for water policy transfer as perceived by the

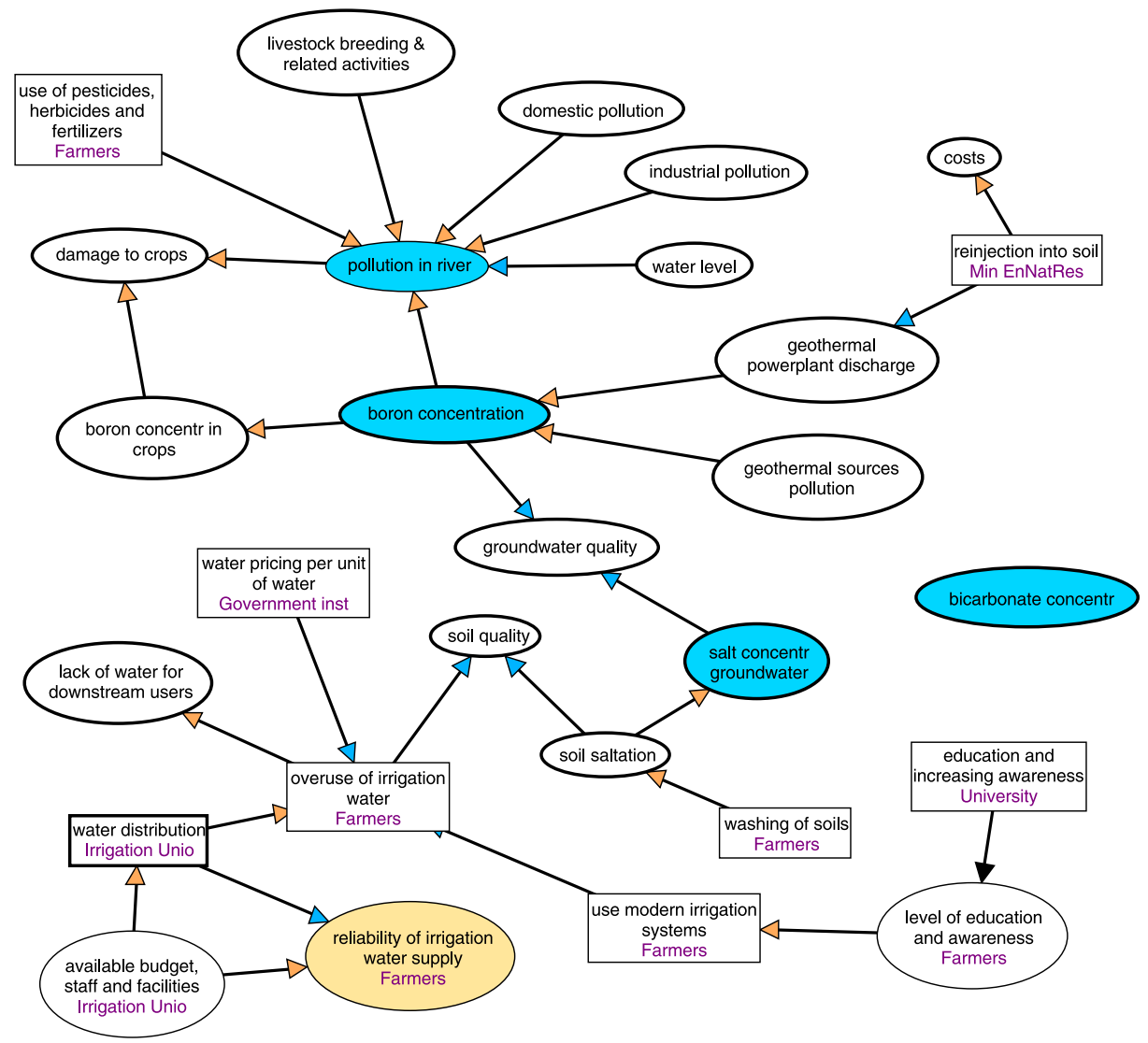

Fig. 3 Example of a causal map for one of the actors in the Büyük Menderes River Basin 
local actors at the target site in Turkey. This comparative analysis was based on standard queries featured in the DANA software. Using the causal maps as a basis, these analyses include frequency counts of the objectives, factors and instruments mentioned by multiple actors. Details of the algorithms programmed in DANA can be found in Bots et al. (2000). No further statistical analysis was performed on the interviews and causal maps.

\subsubsection{Main Problems in the River Basin According to the Actors}

A first step in the analysis was to review the main factors that play a role in river basin management according to the actors. The results of this are shown in Table 2. This table contains a sorted list of problem categories; each problem category contains certain factors, based on a factor frequency analysis of DANA in the constructed actor models. The different categories are shown in the first column, while their overall relevance is shown in the second column, expressed as the number of actors that mentioned factors related to a category as a fraction of the total of nineteen actors. In the last two columns the relevance for respectively the twelve actors from Aydin and the seven actors from Denizli is specified, to see if there is a difference in the perceptions between the downstream and upstream actors.

The first category in the table is a special category, "Pollution at large", which is used to indicate that every actor mentioned factors related to pollution. This category comprises the different types of pollution specified in the separate categories given in Table 2, such as industrial, agricultural, and domestic pollution, and boron pollution from the geothermal sources. The interviewees considered these geothermal sources, especially the geothermal power plant, to be an important source of boron, which was believed to affect crop growth, and possibly human health.

Administrative and institutional issues were also mentioned frequently, referring to problems such as the lack of co-ordination between organizations, limited budgets, staff, and facilities of government institutions, and the influence of politicians on the development and implementation of policies and regulations.

Table 2 Relevance of problem categories (fraction of respondents that mentioned a problem)

\begin{tabular}{llll}
\hline Name of category & Total & Aydin & Denizli \\
\hline Pollution at large & 1.00 & 1.00 & 1.00 \\
Administrative and institutional factors & 0.95 & 1.00 & 0.86 \\
Industrial pollution factors & 0.95 & 1.00 & 0.86 \\
Agriculture \& irrigation factors & 0.79 & 0.75 & 0.86 \\
(Agricultural pollution) & 0.37 & 0.35 & 0.57 \\
(Other factors related to agriculture) & 0.68 & 0.58 & 0.86 \\
Domestic pollution factors & 0.74 & 0.83 & 0.57 \\
General water and soil quality & 0.68 & 0.58 & 0.86 \\
Geothermal boron pollution factors & 0.63 & 0.75 & 0.43 \\
Impacts on water \& soil quality outside pollution & 0.37 & 0.58 & 0.00 \\
Water quantity (other than agriculture) & 0.37 & 0.42 & 0.29 \\
Nature conservation & 0.16 & 0.17 & 0.14 \\
Tourist activities & 0.11 & 0.17 & 0.00 \\
Rest category & 0.53 & 0.75 & 0.14 \\
\hline
\end{tabular}


The importance of agriculture and irrigation was also acknowledged by a majority of actors. This is explained by the fact that agriculture is by far the largest water user in the basin (Yilmaz et al. 2009). Agriculture was seen to cause pollution and environmental degradation due to the use of pesticides and fertilizers, but also due to inadequate irrigation and drainage methods that caused increased soil salinity. Agriculture was also seen to suffer from pollution. Here, decreased crop production and soil problems were most mentioned. This local perception is backed by more recent research that also identifies low quality irrigation as a reason for low irrigation efficiency, particularly in the Aydin region (Yilmaz et al 2009: 1092).

There were differences in the characteristics of the upstream and downstream regions of the Büyük Menderes river basin. An important part of the polluting industrial activities were located in the upstream provinces of Denizli and Uşak, while downstream there was more tourism and there were some vulnerable internationally recognized wetland-areas. Despite these differences, the perceptions about the main water management issues largely overlapped among upstream and downstream actors. The actors in Denizli also recognized the pollution problems, even if the downstream actors suffered most from these problems.

\subsubsection{Mechanisms to Address Problems: Policy Instruments}

Local actors had clear ideas about the instruments that they considered promising ways to support better river basin management, as shown in Table 3 . The contents of this table are derived in a manner similar to those of Table 2, but with the difference that Table 3 is based on an analysis of instruments, whereas Table 2 is

Table 3 Policy instruments and the frequency with which respondents mentioned them

\begin{tabular}{|c|c|c|c|}
\hline Instrument categories and names & Freq & Instrument categories and names & Freq \\
\hline \multicolumn{2}{|l|}{ Pollution } & \multicolumn{2}{|l|}{ Agriculture and irrigation } \\
\hline Industrial wastewater treatment & 8 & Land reconsolidation and development & 7 \\
\hline \multirow{2}{*}{$\begin{array}{l}\text { Financial support wastew. treatment } \\
\text { plants }\end{array}$} & \multirow[t]{2}{*}{7} & (limit) use agro-chemicals & 7 \\
\hline & & Use modern irrigation systems & 4 \\
\hline (limit) use of agro-chemicals & 7 & Stimulate modern agricult. techniques & 3 \\
\hline Domestic wastewater treatment & 6 & Volumetric water pricing & 3 \\
\hline \multirow{2}{*}{$\begin{array}{l}\text { Pollution standards based on } \\
\text { next water use }\end{array}$} & \multirow[t]{2}{*}{4} & Rest category & \multirow{4}{*}{7} \\
\hline & & Education and increasing awareness & \\
\hline Re-inject geothermal water into soil & 4 & & \\
\hline $\begin{array}{l}\text { Advanced (chemical) wastewater } \\
\text { treatment }\end{array}$ & 3 & & \\
\hline $\begin{array}{l}\text { Share treatment plants for } \\
\text { industrial areas }\end{array}$ & 3 & & \\
\hline \multicolumn{4}{|l|}{ Administrative and Institutional } \\
\hline $\begin{array}{l}\text { Monitoring and control of law } \\
\text { implementation }\end{array}$ & 8 & & \\
\hline Land reconsolidation and development & 7 & & \\
\hline $\begin{array}{l}\text { Pollution standards based on next } \\
\text { water use }\end{array}$ & 4 & & \\
\hline Establish and enforce land use plans & 4 & & \\
\hline Development of new laws & 3 & & \\
\hline Volumetric water pricing & 3 & & \\
\hline
\end{tabular}


based on an analysis of factors (including objectives). The instruments in Table 3 are not fully developed mechanisms, in the sense of causal chains that contain various factors. Rather, these instruments are located at the 'start' of such chains. Some instruments, especially those in the 'Administrative and Institutional' category, clearly concern the use of policy mechanisms, such as pricing mechanisms. However, many instruments refer to more technical interventions, which would not be difficult to implement technically speaking, but for which finding the necessary funds, people and equipment would be the real challenge.

When specifically asked about the establishment of a river basin organization as an institutional mechanism for co-operation and co-ordination, the actors were supportive of the idea. The opinions differed on who should be the members of such a new river basin management organization and on who should take the lead in its establishment. The latter would be a role contested by the three main governmental bodies: the Ministry of Environment, the Directorate for State Hydraulic Works (DSI) and the Provincial Governors. Setting up a completely new and independent river basin organization was supported as idea for the long-term, but not for the short-term. Finally, some respondents mentioned that if the implementation of existing laws and regulations was improved, the need for a new river basin management organization would decrease.

\subsubsection{Summarizing the Results of the Comparative Analysis of Local Beliefs}

There is a rich and diverse picture of the local policy problems and their solutions among local actors. On a detailed level, important disagreements exist, but, on a higher level of abstraction, the contours of a shared problem diagnosis are clearly visible. Local actors can be considered to be quite aware of local problems and needs in relation to water resources management, and there also is sufficient consensus about the main problems and needs. This indicates that there is sufficient basis to proceed with a policy transfer process, looking for experiences elsewhere that may help local actors to address their problems.

\subsection{Step 4: Selecting Potential Source Sites and Experiences}

The analysis of the causal beliefs held by local actors suggests that they would be most helped by mechanisms that help to implement technical and operational measures in a situation of limited resources and budgets for water resources management, with local politicians that are sometimes corrupted by short-term wins, and ineffective coordination and cooperation among government institutions. Specific needs include wastewater treatment facilities to reduce industrial, domestic and geothermal (boron) pollution; monitoring and enforcement of compliance with existing laws and regulations; and improvements in agricultural practices for irrigation and the use of agro-chemicals.

This assessment leaves open several possibilities when it comes to potential sources for policy transfer. The context factors suggest looking for positive experiences in situations with similar resource limitations and problems with coordination and transparency in governance. The problems and ideas of possible solutions, suggest looking at experiences with specific (low-cost) techniques to cope with geothermal (boron) pollution and wastewater treatment, improved agricultural practices, and mechanisms for coordination and cooperation in water resources management. 
However, in the case reported here, the selection of a suitable source site was not in the hands of the local actors. Rather, as part of the political process of a possible future EU accession of Turkey, the EU Water Framework Directive had been selected as the main source. Thus, the next step in this case is based on the analysis of a source that was selected without the analysis described above. What this means for the evaluation of the approach reported here, is discussed in Section 5 of the paper.

\subsection{Step 5: Extracting Policy Models and Mechanisms from Selected Sources}

The European Parliament and Council of the European Union adopted the Water Framework Directive in 2000 as a framework for water policy in its member states (EU 2000). The WFD was a somewhat unusual source for policy transfer, as there were no actual experiences with its full implementation in EU Member Countries. Rather, the directive reflected experiences and insights in water policy and governance in those countries that had been reviewed, discussed, and finally accepted in various EU platforms and decision-making structures.

Within the EU, the insights embodied in the Water Framework Directive are being applied and as experience with their implementation grows, learning continues. For non-EU member countries, the Water Framework Directive has been suggested as positive step towards improved water governance, an example that might inspire and inform countries that are seeking models and approaches to strengthen their water governance systems (Van der Sommen 2006; WWAP 2006, 471).

Following the general guidelines provided elsewhere for the reconstruction of policy models (e.g. Bardach 2004; Rose 2005; Barzelay 2007), the main mechanisms included in the WFD could be identified by a review of the text of the directive (EU 2000) and by its discussion in scientific papers and international reports (Page and Kaika 2003; Van der Sommen 2006; WWAP 2006; Steyaert and Ollivier 2007; Ker Rault and Jeffrey 2008). The latter emphasize four important mechanisms as key features of the WFD: administrative coordination at the river basin level, integrated and systematic planning, stakeholder participation, and using economic mechanisms in water management.

\subsubsection{Mechanisms for Administrative Coordination at the River Basin Level}

The WFD calls for the establishment of River Basin Districts as the main planning and policy unit for water resources management. Administrative arrangements should be coordinated within such River Basin Districts, and the competent authority for each District should be identified. For each River Basin District, a River Basin Management Plan should be produced. Some EU member countries already used this river basin planning approach, but for others this signified an important shift: managing water based on natural rather than administrative boundaries (Page and Kaika 2003).

\subsubsection{Mechanisms for Integrated and Systematic Planning}

River Basin Management Plans should be developed through a comprehensive and systematic planning approach focused on ecology and water quality and driven by 
environmental objectives that relate to water bodies (cf. Van der Sommen 2006; Steyaert and Ollivier 2007). This approach is modeled after the 'DPSIR' framework (Driving forces, Pressures, State, Impacts and Responses) and related planning frameworks that are being used and advanced by the OECD, the European Environmental Agency and various UN organizations. It requires, among other things, the identification of the ecological state of water bodies, based on an assessment of hydromorphological, physicochemical and biological indicators. Also, the anthropogenic pressures on surface waters should be assessed, including sources and substances of pollution, water abstractions for various uses, seasonal variations in demand, water transfers, flow diversions, water balances, morphological alterations, land use patterns and activities that are likely to have significant impacts.

\subsubsection{Mechanisms for Participation}

The WFD states that the involvement of all interested parties is required in the river basin management planning cycles. The Directive itself contains the minimum requirement to publish draft working schedules and draft river basin management plans, while allowing sufficient time for comments by interested parties. Since publication of the WFD, further guidance on participation has been made available and the attention for participation is emphasized as one of the main innovations embodied in the WFD (Ker Rault and Jeffrey 2008; Page and Kaika 2003; Van der Sommen 2006; Steyaert and Ollivier 2007).

\subsubsection{Economic Mechanisms in Water Management}

A fourth mechanism incorporated in the WFD is the adoption of an economic perspective in water management (Page and Kaika 2003; Van der Sommen 2006; Steyaert and Ollivier 2007). This requires attention for the cost-effectiveness of water policy measures, but also for the use of water charges to recover the costs for water service delivery. This fourth mechanism was not addressed in the Turkish case reported here, as this was not considered appropriate within the time frame of the project.

\subsection{Step 6: Evaluating Experiences and Mechanisms for Use at the Target Site}

A comparison of local ideas and priorities in Turkey with the ideas and mechanisms in the WFD shows that there are important areas of agreement and that they are not necessarily in contradiction. Thus, in principle the implementation of the WFD and its main mechanisms might work in Turkey, if there is sufficient political support. However, the comparison also shows that the two emphasize different issues. What does this mean for the usefulness of the WFD as a source for policy transfer to improve water resources management in Turkey? In response to this question, at least four relevant insights emerge from the analytical approach followed above.

One, the WFD offers a mechanism to improve coordination by means of the establishment of a new institution at the river basin scale. However, in the Büyük Menderes river basin in Turkey, the main problems are considered to be the implementation and enforcement of existing plans and regulations and the functioning 
of the existing institutions. If there are problems with the functioning of existing institutions, it is not clear why a new river basin organization as platform for coordination would not suffer from similar problems.

Two, limited funds and resources are clearly a concern in the Büyük Menderes river basin, but the actors there share a consensus about what their urgent problems are and about where to look for solutions. Nevertheless, the planning mechanisms in the WFD would require them to embark first on a comprehensive assessment process, to establish the status and pressures on their water bodies, to make absolutely sure they are targeting the right problems and that they are considering the most cost-effective packages of measures. Although such complete assessments make analytical sense, in the face of competition for scarce planning resources it may be a luxury that cannot, and need not, be afforded. Sound planning is a balancing act between analytical rigor and practical constraints. The WFD elaborates on the standards for analytical rigor, but in the Büyük Menderes river basin practical constraints call the appropriateness of such high analytical standards into question. Here, the equivalence of planning resources between the target site and the average EU country may pose limits to policy transfer (see Rose 1993: 127).

Three, related to the previous point, the WFD contains inconsistencies between the mechanisms of planning and participation. The WFD subscribes to the ideal of active participation in river basin planning procedures, but also prescribes the required content of those same planning procedures in a detailed way. If participation and input from actors is taken seriously, and if the local actors single out specific priority sources and substances of pollution, there is less need for detailed assessments that cover a long range of items. Rather than spending money on a full-scale comprehensive assessment of all possible problems and complications that water scientists and experts could think of, a more logical start in the Büyük Menderes river basin would be to investigate the suspicions of local actors on priority problems related to point-source pollution from industrial, domestic and geothermal sources.

Four, the WFD incorporates a planning mechanism for integrated water resources management, whereby it integrates across the ecological dimension. Such integration is not value-free, however. The WFD organizes the river basin planning procedures around ecological objectives, suggesting that in all cases the primary water management objective should be to reach a good ecological status of all water bodies. Of course, no-one could be against a healthy natural water system, but healthy water bodies are not an end in themselves for everyone. Yet the WFD elevates them to that level. Thus, the ecological perspective is dominant, rather than a utilitarian perspective that puts human activities central (Steyaert and Ollivier 2007). Although the WFD provides room for a more utilitarian approach through its use of costbenefit assessment of measures and through pricing mechanisms, these instruments are subsumed under an ecological perspective. In many EU countries it may be sensible to promote the ecological perspective to balance the utilitarian perspective that may have dominated government policies and practices in the past. This is a normative choice, which is not necessarily acceptable in the Büyük Menderes river basin. Thus, the congruity between the values of policy makers in Turkey and the WFD's values may be less than desirable for policy transfer (see Rose 1993: 141; cf. Acharya 2004). 


\subsubsection{In Sum: Adopt, Adapt or Reject?}

These insights suggest that, of the four main mechanisms in the WFD, especially the planning mechanisms in the WFD is in need of adaptations. Furthermore, it is not clear that WFD implementation of the other mechanisms will indeed solve the local priority problems. Thus, the WFD should not be simply copied to the Büyük Menderes river basin. At least, not in a version of policy transfer that emphasizes the analytical dimension over the political considerations.

This finding for this case is not surprising, as the selection of the WFD as a source for policy learning did not take into account an explicit analysis of the needs and priorities of local actors. There were political considerations and pressures to consider and adopt EU norms and practices in Turkey as a part of ongoing political discussions, both domestically and internationally.

\section{Discussion}

\subsection{Usefulness of the Approach to Meet Needs for Analytical Support to Local Actors}

The approach outlined in Section 3 was intended to address an apparent need for analytical support to local actors in the early phases of policy transfer processes. Does the case application of this approach confirm the existence of this need? And does the used approach meet this need in practice?

In relation to the first question, the case reported here confirms that indeed analytical support for local actors in the initial phase of policy transfer can be useful and can yield information that could lead to different decisions during the process. What actually happened at the target site provides the counterfactual: evidence of what could happen without analysis during the initial phase. In this case, policy transfer was initiated primarily from a political perspective. Mainly due to pressures from abroad and national political motives, the transfer of the WFD was set as a project objective - without a prior analysis of the local, context-specific problems it was supposed to solve. The described analysis suggested that apart from the WFD, also other experiences could be considered as sources for policy transfer. In later phases of the policy transfer process, it helped to evaluate the usefulness of the WFD to address local problems.

Thus, the case supports the claim that there is a need for an approach such as the one reported here. However, the case also confirms that, despite its plausible substantive contributions, this analytical approach still may not be used in processes dominated by political concerns. Given the current lack of analytical support for the early phases, this case will not be unique in being initiated on a political, rather than an analytical basis. Even with analytical support tools, it will take time to change this.

One group of actors that could, and should, play a role in changing this current attitude, are the international experts and advisors that are often involved in policy transfer processes-especially when these processes involve international funding institutions. These international advisors should be cautious to assess the local needs for policy transfer before championing a new foreign policy model as a solution. Still, 
whether the need for analytical support is felt depends on the situation and the room for analytical inputs in processes with a strong political dimension.

The second question is partly answered by repeating that the approach provided new and relevant insights, which otherwise would have been overlooked. However, something more needs to be said about it here. Specifically, one can question if the approach really resulted in valid, relevant and new information, according to the local actors and external experts involved. Here, an evaluation of the performed analysis with two separate groups, of local actors and external project experts, showed that both groups considered the outcomes of the first three steps reported here as relevant, new and valid (Hermans 2005). This does not mean that the approach is the only, or even the best, way to address the need for analytical support in the initial phase of policy transfer. But at least it was, in the case reported here, an adequate way to meet these needs.

\subsection{Revisiting the Assumptions Underlying the Approach}

The approach was based on the assumption that causal explanations would not only be useful to analyze source site experiences, but also to identify needs at the target site. This requires explicit attention for mechanisms and context factors. However, in the case, little explicit attention has been paid to relevant context factors in the design of the interviews. Still, without explicit attention for context, the most salient factors of context-specificity emerged anyway. They emerged when evaluating the potential usefulness at the target site of the mechanisms from abroad, such as the issues of limited resources, general consensus about priorities, and problems with an institutional setting that went beyond the policy domain of water management.

In fact, the use and role of context factors seems an unresolved issue also in the policy transfer and evaluation literature underlying the use of causal explanations for looking at source sites. Whereas some authors explicitly refer to "context" as a key element in causal explanations (Pawson and Tilley 1997), others work on the presumption that "the same configuration of social mechanisms can be activated by different factors, including contrivances and their context..[and]...that the same configuration of social mechanisms, once activated, will tend to cause similar event trajectories in different undertakings" (Barzelay 2007: 529). Still attention is paid to context factors, but as "contingent features" that are closely related to the mechanisms (Bardach 2004: 211; cf Rose 1993: 118). This suggests that one would probably come across the main context factors when analyzing mechanisms-which was what happened in the case here.

Another assumption underlying the approach was that it would be useful to start with consultations with individual actors, as agreement or consensus among local actors could not be assumed. In the reported case, it turned out that there was a certain degree of consensus at the target site about priority problems and promising solutions. In this case, questions of cost-effectiveness are more easily raised for the choice to start with individual consultations rather than for instance a plenary meeting. Still, the assumption remains that consensus cannot simply be assumed at the start, and that, to be on the safe side, individual consultations should be preferred. However, the correctness for cases in which there is no consensus cannot be assessed based on the available experience. 
If there would be no consensus, it does seem likely that there would be a more pressing need for additional support, more explicitly dealing with the political dimension. This is beyond scope of this paper, which focuses on analytical support around the substance of policy transfer. For cases which lack consensus, it seems worthwhile to turn to the literature on negotiations, mediation and consensus-building for ideas and future studies (e.g. Susskind and Thomas-Larmer 1999; Raiffa et al. 2002; Fisher et al. 1991).

\subsection{The Use of Dynamic Actor Network Analysis as a Method within this Approach}

The approach used Dynamic Actor Network Analysis (DANA) as a method to analyze the perceptions of local actors. This method performed adequately, in light of the above discussions. However, it is not possible to say whether or not some other methods would not have performed equally well. In this regard, the case did not provide insights that shed new light on the reasoning as outlined in Section 3.3 of the paper. In short: other methods, especially certain problem structuring methods, might have sufficed as well, but DANA does have some specific features that make its use attractive when an important aim is to compare causal beliefs of multiple actors.

\subsection{Supporting the Final Phases of Policy Transfer}

The focus in the design of the approach has been on the initial phase of policy transfer. For the subsequent phases, some questions still remain. In particular, the question of how the evaluation of source site experiences can be supported at a target site. Here, a rather intuitive approach has been used, with the main difference with available approaches being that the evaluation in this approach is firmly rooted in an assessment of local beliefs, needs and priorities the target site. This enables an evaluation based on a comparison of these local conditions with the mechanisms available in a source for policy transfer. Nevertheless, for this evaluation phase, further analytical guidelines could be developed. Besides a closer reading of the policy transfer literature on specific suggestions for the final phases of evaluation and implementation, also the field of decision analysis and decision modeling may offer useful starting points.

\section{Conclusions}

Policy transfer and learning from the experience of others are important and powerful instruments for policy makers to confront local water resources management problems. These policy transfer processes typically involve different stages and are known to feature a political as well as an analytical dimension. The available support for the analytical dimension focuses on the experiences at a source site, through the analysis of mechanisms that offer causal explanations of those experiences. However, analytical support for the local actors at the target site is also needed. Here, an approach that involves the reconstruction and comparison of perceptions of different local actors may offer useful support for the initial phase of policy transfer. 
This approach was applied to a case in Turkey, to explore if it would help local actors there to make informed decisions in different phases of a policy transfer process. The case application confirmed that the approach is feasible in real-world situations and that it yields useful knowledge to support local actors at the target site. However, with just one case, any claims related to the proposed approach should be guarded with caution.

Among the unresolved issues is the assumption that the approach also provides a useful basis for further negotiations among local actors when there is little or no consensus at the start of a policy transfer process. Also, the approach focuses on the initial phase of policy transfer, leaving further elaborations of support in later phases as items for future research. Finally, useful knowledge may be generated, but still, this is less likely to be used when the political dimension is dominant. Providing an approach for analytical support alone will not change this, but at least it offers a tool to those who want to provide analytical support to do so.

All in all, it remains plausible that there is a need for an approach that enables local actors to probe and to communicate their views and beliefs, relating foreign experiences and international policy guidelines to the specific problems they are facing. The case results warrant a cautious optimism about the usefulness of the approach proposed in this paper to support informed decision-making about policy transfer by local actors at a target site.

Open Access This article is distributed under the terms of the Creative Commons Attribution Noncommercial License which permits any noncommercial use, distribution, and reproduction in any medium, provided the original author(s) and source are credited.

\section{References}

Acharya A (2004) How ideas spread: whose norms matter? Norm localization and institutional change in Asian regionalism. Int Organ 58(2):239-275

Argyris C, Schön DA (1996) Organizational learning II. Theory, method, and practice. AddisonWesley, Reading

Bardach E (2004) Presidential address-the extrapolation problem: how can we learn from the experience of others? J Policy Anal Manage 23:205-220

Barzelay M (2007) Learning from second-hand experience: methodology for extrapolation-oriented case research. Governance 20:521-543

Bennett CJ (1991) How states utilize foreign evidence. J Public Policy 11(1):31-54

Bots PWG (2009) Dynamic actor network analysis. Software and overview. http://dana. actoranalysis.com

Bots PWG, Van Twist MJW, Van Duin JHR (2000) Automatic pattern detection in stakeholder networks. 33rd Hawaii International Conference on System Sciences. IEEE, Los Alamitos

Chen HT, Rossi PH (eds) (1992) Using theory to improve program and policy evaluations. Greenwood, New York

Collins KB, Ison RL (2010) Trusting emergence: some experiences of learning about integrated catchment science with the environment agency of England and Wales. Water Resour Manage 24:669-688

De Jong M, Edelenbos J (2007) An insider's look into policy transfer in transnational expert networks. Eur Plan Stud 15:687-706

Dolowitz DP (2000) Introduction. Special issue on policy transfer. Governance 13(1):1-4

Dolowitz DP, Marsh D (2000) Learning from abroad: the role of policy transfer in contemporary policy-making. Governance 13(1):5-24

European Union (2000) Directive of the European Parliament and of the Council 2000/60/EC Establishing a Framework for Community Action in the Field of Water Policy. Luxembourg 23 October 2000 
Evans M, Davies J (1999) Understanding policy transfer: a multi-level, multi-disciplinary perspective. Public Adm 77(2):361-385

Fisher R, Ury W, Patton B (1991) Getting to yes: negotiating agreement without giving in, 2nd ed. Random House Business Books, London, reprinted 1999

Hermans LM (2005) Actor analysis for water resources management: putting the promise into practice. Eburon, Delft

Hermans LM, Muluk CB (2002) Actor analysis for the Büyük Menderes River basin management plan. Report for the IWFD Turkey Project, Delft/Ankara

Hermans LM, Thissen WAH (2009) Actor analysis methods and their use for public policy analysts. Eur J Oper Res 196:808-818

Hommes S, Vinke-deKruijf J, Otter HS, Bouma G (2009) Knowledge and perceptions in participatory processes: lessons from the delta-region in the Netherlands. Water Resour Manage 23:1641-1663

James O, Lodge M (2003) The limitations of 'policy transfer' and 'lesson drawing' for public policy research. Political Studies Review 1:179-193

Ker Rault PA, Jeffrey PJ (2008) Deconstructing public participation in the Water Framework Directive: implementation and compliance with the letter or with the spirit of the law? Water Environ J 22:241-249

Mingers J, Rosenhead J (2004) Invited review_-problem structuring methods in action. Eur J Oper Res 152:530-554

Page B, Kaika M (2003) The EU water framework directive: Part 2. Policy innovation and the shifting choreography of governance. Eur Environ 13:328-343

Pawson R, Tilley N (1997) Realistic evaluation. Sage, London

Raiffa H, Richardson J, Metcalfe D (2002) Negotiation analysis. The science and art of collaborative decision making. Harvard University Press, Cambridge

Rittel HWJ, Webber MM (1973) Dilemmas in a general theory of planning. Policy Sci 4:155-169

Robertson DB (1991) Political conflict and lesson-drawing. J Public Policy 11(1):55-78

Rose R (1993) Lesson-drawing in public policy: a guide to learning across time and space. Chatham House, Chatham

Rose R (2005) Learning from comparative public policy. A practical guide. Routledge, Abingdon, UK

Steyaert P, Ollivier G (2007) The European water framework directive: how ecological assumptions frame technical and social change. Ecol Soc 12(1):25

Stokes Berry F, Berry WD (2007) Innovation and diffusion models in policy research. In: Sabatier PA (ed) Theories of the policy process. Westview, Boulder, 223-260

Susskind L, Thomas-Larmer J (1999) Conducting a conflict assessment. In: Susskind L, McKearnan S, Thomas-Larmer J (eds) Consensus building handbook. Sage, Thousand Oaks, CA

Swatuk LA (2005) Political challenges to implementing IWRM in Southern Africa. Phys Chem Earth 30:872-880

Van der Sommen J (ed) (2006) Europe, water, and the world. European Regional Document for the Fourth World Water Forum held in Mexico City, March 2006.

Van der Zaag P (2007) Asymmetry and equity in water resources management; critical institutional issues for Southern Africa. Water Resour Manage 21(12):1993-2004

WWAP-World Water Assessment Programme (2006) Water: a shared responsibility, The UN World Water Development Report 2. UNESCO/Berghahn Books, Paris/New York

Yilmaz B, Yurdusev MA, Harmancioglu NB (2009) The Assessment of Irrigation Efficiency in Buyuk Menderes Basin. Water Resour Manage 23:1081-1095 